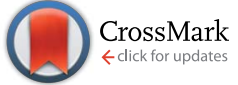

Cite this: RSC Adv., 2017, 7, 6447

Received 1st November 2016 Accepted 10th January 2017

DOI: $10.1039 / c 6 r a 26142 f$

www.rsc.org/advances

\title{
Performance of bimetallic PdRu catalysts supported on gamma alumina for 2-ethylanthraquinone hydrogenation $\uparrow$
}

\begin{abstract}
Jinli Zhang, ${ }^{\text {ab }}$ Kaige Gao, ${ }^{a}$ Suli Wang, ${ }^{a}$ Wei Li ${ }^{a}$ and You Han*a
A series of bimetallic $\mathrm{PdRu}$ catalysts supported on $\gamma-\mathrm{Al}_{2} \mathrm{O}_{3}$ were prepared by incipient wetness impregnation method and were assessed in the 2-ethylanthraquinone hydrogenation process. It is found that the addition of Ru to Pd can improve the catalyst's activity and maintain high selectivity at the same time for 2-ethylanthraquinone hydrogenation. Several analysis techniques including $\mathrm{N}_{2}$ adsorptiondesorption, ICP-AES, XRD, TEM, $\mathrm{H}_{2}$-TPR, $\mathrm{H}_{2}$-TPD and XPS were adopted for characterizing the structural and electronic properties of the samples. It is revealed that PdRu bimetallic system shows stronger hydrogen desorption behavior in contrast to the monometallic catalysts. In addition, the higher fraction of $\mathrm{Pd}^{2+}$ and the presence of $\mathrm{Ru}^{4+}$ in the $\mathrm{PdRu}$ system may act as the electrophilic sites for the adsorption and activation of the $\mathrm{C}=\mathrm{O}$ of the 2-ethylanthraquinone molecule through the lone electron pair of the oxygen atom. These factors may be attributed to the superior performance of PdRu bimetallic samples for 2-ethylanthraquinone hydrogenation.
\end{abstract}

\section{Introduction}

As an environmentally friendly oxidizing agent, hydrogen peroxide $\left(\mathrm{H}_{2} \mathrm{O}_{2}\right)$ has been increasingly used in many fields, such as electronics, chemical synthesis, textile and pharmaceutical industries, paper bleaching, mining and waste water treatment, etc. $^{\mathbf{1}^{-7}}$ By far, the anthraquinone (EAQ) process involving sequential hydrogenation and oxidation of an anthraquinone derivative (typically 2-ethylanthraquinone) is the most popular route for commercial scale production of $\mathrm{H}_{2} \mathrm{O}_{2} \cdot{ }^{8-11}$ Specifically, 2-ethylanthraquinone (2-EAQ) in an appropriate mixture of solvents (typically C9-C10 aromatics and trioctyl phosphate) is hydrogenated catalytically to yield 2-ethylanthrahydroquinone $\left(\mathrm{EAQH}_{2}\right)$. Then $\mathrm{EAQH}_{2}$ is oxidized to produce $\mathrm{H}_{2} \mathrm{O}_{2}$ with regeneration of the EAQ. ${ }^{12,13}$ However, various hydrogenation products besides $\mathrm{EAQH}_{2}$ are produced in the hydrogenation process due to further hydrogenation of EAQ, such as 2-ethyl5,6,7,8-tetrahydroanthracene-9,10-diol $\quad\left(\mathrm{H}_{4} \mathrm{EAQH}_{2}\right)$, 2-ethyl1,2,3,4,5,6,7,8-octahydroanthracene-9,10-diol $\left(\mathrm{H}_{8} \mathrm{EAQH}\right)$ and 2-ethylanthrone (EAN), etc. Among them, only $\mathrm{H}_{4} \mathrm{EAQH}_{2}$ can be oxidized to generate $\mathrm{H}_{2} \mathrm{O}_{2}$ and $\mathrm{H}_{4} \mathrm{EAQ}$, which can also be used in the production cycle of $\mathrm{H}_{2} \mathrm{O}_{2}$. Therefore, EAQ and $\mathrm{H}_{4} \mathrm{EAQ}$ are usually called as "active quinones" and other hydrogenation

${ }^{a}$ School of Chemical Engineering \& Technology, Tianjin University, Tianjin 300072, $P$. R. China. E-mail: yhan@tju.edu.cn; Tel: +86-22-8535-1149

${ }^{b}$ School of Chemistry \& Chemical Engineering, Shihezi University, Xinjiang, Shihezi 832000, P. R. China

$\dagger$ Electronic supplementary information (ESI) available. See DOI: 10.1039/c6ra26142f products which are not capable to produce $\mathrm{H}_{2} \mathrm{O}_{2}$ are considered as "degradation products". ${ }^{\mathbf{1 4 , 1 5}}$

Hydrogenation of anthraquinone in the presence of metal catalyst is the key reaction in the synthesis of $\mathrm{H}_{2} \mathrm{O}_{2}$ through anthraquinone route. Supported palladium catalyst are commonly used in this process. ${ }^{16,17}$ Considering the growing demand of $\mathrm{H}_{2} \mathrm{O}_{2}$, development of a catalyst with superior performance and relatively low price is one of the most important issues to satisfy the requirements of efficiency and economy.

It is well known that supported bimetallic catalysts have attracted much attentions in the catalysis field, as such combination of metals can often lead to superior catalytic performance due to the synergetic effects. ${ }^{18}$ To improve the catalytic performance of $\mathrm{Pd}$ based catalysts for hydrogenation reactions, the effects of a second metal component additives, including $\mathrm{Au},{ }^{19-22} \mathrm{Ag},{ }^{23} \mathrm{Pt},{ }^{24,25} \mathrm{Zn},{ }^{26} \mathrm{Cu},{ }^{27} \mathrm{Co},{ }^{28} \mathrm{Sn},{ }^{29,30} \mathrm{Ni},{ }^{31,32}$ etc. have been investigated extensively.

For 2-ethylanthraquinone hydrogenation process, continuous efforts have also been made to improve the catalytic performance by incorporating a second metal into Pd catalysts. ${ }^{33,34}$ Our previous work has reported that addition of $\mathrm{Au}$ to $\mathrm{Pd}$ can enhance the catalyst's activity for the hydrogenation of 2-ethylanthraquinone. ${ }^{35}$ However, considering its higher price of $\mathrm{Au}$ (almost twice of Pd), the application of this catalyst is also restricted. Hence, it remains a big challenge to find promising candidates in order to reduce the cost of catalysts to meet the requirements of economy.

$\mathrm{PdRu}$, one of the most widely-studied bimetallic catalysts, has been reported to be active for selective hydrogenation of unsaturated organic compounds. Ntainjua et al. reported that addition of $\mathrm{Ru}$ enhanced the activity of $\mathrm{Pd} / \mathrm{TiO}_{2}$ for direct 
synthesis of $\mathrm{H}_{2} \mathrm{O}_{2}$ from hydrogen and oxygen. ${ }^{36}$ Luo et al. reported that $\mathrm{PdRu} / \mathrm{TiO}_{2}$ was not only exceptionally active but also excellent, sustained selectivity for the catalytic hydrogenation of levulinic acid to $\gamma$-valerolactone. ${ }^{37}$ Huang et al. found that bimetallic PdRu catalysts supported on mesoporous silica nanoparticle (MSN) showed 5 times higher activity than that of $\mathrm{Pd} / \mathrm{MSN}$ towards the liquid-phase hydrogenation of phenol. ${ }^{38}$ Qiu et al. reported that the cinnamaldehyde conversion and the selectivity towards the hydrogenation of $\mathrm{C}=\mathrm{O}$ bond over $\mathrm{Pd}-\mathrm{Ru}$ / PCNT catalyst was better than Pd/PCNT and Ru/PCNT catalysts under the same reaction conditions, which might be due to the synergic effect of Pd and Ru metals or the promoting effect of $\mathrm{Ru}$ metal. ${ }^{39}$ Chen et al. reported bimetallic PdRu catalysts on porous alumina spheres behaved superior catalytic activity over monometallic ones for selective hydrogenation of dimethyl terephthalate (DMT) to dimethyl cyclohexane-1,4-dicarboxylate (DMCD). ${ }^{40}$ Yu et al. found that bimetallic PdRu nanoparticles could show high activity for hydrogenation of alkene. ${ }^{\mathbf{4 1}}$

Generally, many researches have found the synergistic effect in $\mathrm{PdRu}$ catalysts and proved that PdRu bimetallic systems could exhibited superior performance than monometallic one for some hydrogenation reactions. Inspired by these encouraging findings, addition of $\mathrm{Ru}$ to $\mathrm{Pd} / \gamma-\mathrm{Al}_{2} \mathrm{O}_{3}$ may be a feasible method to improve its performance for 2-ethylanthraquinone hydrogenation process. In addition, its relatively low price (only eight percent of $\mathrm{Pd}$, four percent of $\mathrm{Au}$ ) may meet the requirement of economy. However, as far as we can see, no studies have been published on supported PdRu bimetallic catalysts for the hydrogenation of 2-ethylanthraquinone. In addition, the promoting roles of $\mathrm{Ru}$ need be further investigated.

In our present work, we attempt to prepare a series of bimetallic $\mathrm{PdRu} / \gamma-\mathrm{Al}_{2} \mathrm{O}_{3}$ catalysts with different $\mathrm{Pd} / \mathrm{Ru}$ mass ratios by incipient wetness impregnation method and extensively investigated their performance for 2-ethylanthraquinone hydrogenation. Several analysis techniques including $\mathrm{N}_{2}$ adsorption-desorption, inductively coupled plasma-atomic emission spectrometry (ICP-AES), powder X-ray diffraction (XRD), transmission electron microscopy (TEM), X-ray photoelectron spectroscopy (XPS) and temperature programmed reduction of hydrogen $\left(\mathrm{H}_{2}\right.$-TPR $)$ /temperature programmed desorption of hydrogen ( $\mathrm{H}_{2}$-TPD) were adopted for offering insights into the reasons for the superior catalytic performance of PdRu bimetallic system.

\section{Experimental}

\subsection{Materials}

$\mathrm{Na}_{2} \mathrm{PdCl}_{4}$ (AR, Energy Chemical, China); $\mathrm{RuCl}_{3} \cdot x \mathrm{H}_{2} \mathrm{O}$ (AR, Aladdin, China); pseudoboehmite (AR, CNOOC Tianjin Chemical Research Institute, China); 2-ethylanthraquinone, trioctyl phosphate and trimethylbenzene (AR, TCI, Japan).

\subsection{Catalyst preparation}

$\mathrm{PdRu} / \gamma-\mathrm{Al}_{2} \mathrm{O}_{3}$ catalysts were prepared by the incipient wetness impregnation method. $\mathrm{Na}_{2} \mathrm{PdCl}_{4}$ was used as the Pd precursor and $\mathrm{RuCl}_{3} \cdot x \mathrm{H}_{2} \mathrm{O}$ as the $\mathrm{Ru}$ precursor. Pseudoboehmite was calcined in air at $600{ }^{\circ} \mathrm{C}$ for $4 \mathrm{~h}$ to obtain $\gamma-\mathrm{Al}_{2} \mathrm{O}_{3}$, then it was used as the support. A slurry of $\gamma-\mathrm{Al}_{2} \mathrm{O}_{3}$ in a $\mathrm{Na}_{2} \mathrm{PdCl}_{4}$ and $\mathrm{RuCl}_{3}$ aqueous solution was stirred at $45^{\circ} \mathrm{C}$ for $1 \mathrm{~h}$. After excess water was evaporated, the impregnated samples were dried at $110{ }^{\circ} \mathrm{C}$ overnight and finally calcined in static air at $450{ }^{\circ} \mathrm{C}$ for $4 \mathrm{~h}$. Four bimetallic catalysts were prepared with the same Pd loading amount $(0.6 \%)$ and varying the $\mathrm{Ru}$ content $(0.4 \%, 0.8 \%, 1.2 \%$, $1.6 \%)$, which were named as $0.6 \mathrm{Pd} 0.4 \mathrm{Ru}, 0.6 \mathrm{Pd} 0.8 \mathrm{Ru}$, 0.6Pd1.2Ru, 0.6Pd1.6Ru, respectively. For comparison, monometallic Pd (mono-Pd) with a metal content of $0.6 \mathrm{wt} \%(0.6 \mathrm{Pd})$ and monometallic $\mathrm{Ru}$ (mono-Ru) catalysts with a metal content of $0.4 \mathrm{wt} \%(0.4 \mathrm{Ru}), 0.8 \mathrm{wt} \%(0.8 \mathrm{Ru}), 1.2 \mathrm{wt} \%(1.2 \mathrm{Ru})$ and $1.6 \mathrm{wt} \%$ $(1.6 \mathrm{Ru})$ were prepared using the same procedures respectively.

\subsection{Catalyst characterization}

The specific surface area, total pore volume and average pore size were measured by low-temperature $\mathrm{N}_{2}$ adsorption-desorption experiment on a Surface Area \& Pore Size Analyzer (Nova 2200e, Quantachrome Instruments, USA) at $-196^{\circ} \mathrm{C}$. Before the analysis, the samples were degassed at $300{ }^{\circ} \mathrm{C}$ for $4 \mathrm{~h}$. Elemental analysis was carried out by inductively coupled plasma-atomic emission spectrometry (ICP-AES) using an Iris Advantage Thermo Jarrel Ash device. XRD patterns were measured on a Bruker D8 Advance diffractometer equipped with a $\mathrm{Si}$ (Li) solidstate detector (SOL-X) and a sealed tube providing $\mathrm{Cu} \mathrm{K} \alpha$ radiation, in a $2 \theta$ angle range from $10^{\circ}$ to $90^{\circ}$ with a scanning rate of $5^{\circ} \mathrm{min}^{-1}$. Transmission electron microscopy (TEM) analysis was carried out using a JEOL JEM2010 microscope under an accelerating voltage of $200 \mathrm{kV}$. XPS was recorded using a Kratos Axis Ultra DLD spectrometer employing a monochromated $\mathrm{Al} \mathrm{K} \alpha \mathrm{X}$ ray source $(h \nu=1486.6 \mathrm{eV})$, hybrid (magnetic/electrostatic) optics, a multi-channel plate and a delayline detector (DLD) to examine the electronic properties of $\mathrm{Pd}$ and $\mathrm{Ru}$ on the catalysts surface. All the binding energies were referenced to the $\mathrm{C} 1 \mathrm{~s}$ peak at $284.8 \mathrm{eV}$. Temperature programmed reduction of hydrogen $\left(\mathrm{H}_{2}\right.$-TPR $)$ and temperature programmed desorption of hydrogen $\left(\mathrm{H}_{2}\right.$-TPD) were performed with an AutoChem BET TPR/TPD (Quantachrome Instruments, USA) connected to a thermal conductivity detector (TCD) to investigate the reducibility and hydrogen desorption property of the catalysts. The classic $\mathrm{H}_{2}$ TPR was as follows: a sample of $100 \mathrm{mg}$ was heated from room temperature to $600{ }^{\circ} \mathrm{C}$ at a heating rate of $10{ }^{\circ} \mathrm{C} \min ^{-1}$ under a flow of $10 \% \mathrm{H}_{2} / \mathrm{Ar}$. The representative $\mathrm{H}_{2}$-TPD was conducted as follows: prior to the absorption, the catalyst was reduced in $10 \% \mathrm{H}_{2} / \mathrm{Ar}$ at $450{ }^{\circ} \mathrm{C}$ for $60 \mathrm{~min}$, then cooled down in pure Ar. Absorbent of $10 \% \mathrm{H}_{2} / \mathrm{Ar}$ was introduced into the system at $40{ }^{\circ} \mathrm{C}$ for $30 \mathrm{~min}$. Afterwards, the system was purged with $\mathrm{Ar}$ for $30 \mathrm{~min}$. Then temperature was ramped from $40^{\circ} \mathrm{C}$ to $450{ }^{\circ} \mathrm{C}$ at a rate of $10{ }^{\circ} \mathrm{C} \min ^{-1}$ in $\mathrm{Ar}$.

The $\mathrm{H}_{2}$-TPR, $\mathrm{H}_{2}$-TPD investigations were performed with fresh catalysts and the $\mathrm{N}_{2}$ adsorption-desorption, ICP, XRD, TEM and XPS investigations were performed using the reduced catalysts.

\subsection{Catalytic performance test}

Prior to the reaction, the samples were reduced at $450{ }^{\circ} \mathrm{C}$ in $10 \%$ $\mathrm{H}_{2} / \mathrm{Ar}$ for $2 \mathrm{~h}$. The hydrogenation experiments were performed 
in an autoclave at a $\mathrm{H}_{2}$ pressure of $0.3 \mathrm{MPa}$ and $60{ }^{\circ} \mathrm{C}$ with a rotating speed of $1000 \mathrm{rpm} .120 \mathrm{~g}$ of 2-ethylanthraquinone was dissolved in $1 \mathrm{~L}$ of a mixed solvent composed of trioctyl phosphate and trimethylbenzene with a volume ratio of $1: 1$ to obtain the working solution. Typically, $0.3 \mathrm{~g}$ catalysts and $60 \mathrm{~mL}$ of the working solution were put into the autoclave. After reacting for a certain time $(5 \mathrm{~min}, 10 \mathrm{~min}, 15 \mathrm{~min}, 20 \mathrm{~min}$, $25 \mathrm{~min}, 30 \mathrm{~min}, 35 \mathrm{~min}$ ), $2 \mathrm{~mL}$ of the hydrogenation products were put into $15 \mathrm{~mL}$ deionized water and oxidized with $\mathrm{O}_{2}$ at room temperature. After that, a $\mathrm{H}_{2} \mathrm{O}_{2}$ aqueous solution was obtained. The content of $\mathrm{H}_{2} \mathrm{O}_{2}$ was analyzed by titration with $\mathrm{KMnO}_{4}$ solution. Prior to titration, $5 \mathrm{~mL}$ of a $3 \mathrm{~mol} \mathrm{~L}^{-1}$ sulfuric acid solution was added to the obtained $\mathrm{H}_{2} \mathrm{O}_{2}$ solution. The catalytic activity is expressed by the following equation:

$$
B=\frac{5}{2} \frac{C V_{0} M}{V}
$$

where $B$ is the hydrogenation efficiency $\left(\mathrm{g} \mathrm{L}^{-1}\right), C$ is the $\mathrm{KMnO}_{4}$ solution concentration $\left(\mathrm{mol} \mathrm{L}{ }^{-1}\right), V_{0}$ is the $\mathrm{KMnO}_{4}$ solution volume (mL), $M$ is the molar mass of $\mathrm{H}_{2} \mathrm{O}_{2}\left(\mathrm{~g} \mathrm{~mol}^{-1}\right)$ and $V$ is the $\mathrm{H}_{2} \mathrm{O}_{2}$ solution volume $(\mathrm{mL})$. The productivity is defined as the weight of $\mathrm{H}_{2} \mathrm{O}_{2}$ produced per gram of palladium per hour.

The concentrations of the initial concentration of EAQ $\left(n^{0}\right.$ (EAQ)), active quinones (EAQ and $\left.\mathrm{H}_{4} \mathrm{EAQ}\right)$ in the working solution after a cycle process, which were denoted as $n^{t}$ (EAQ) and $n^{t}\left(\mathrm{H}_{4} \mathrm{EAQ}\right)$ were analyzed with a high performance liquid chromatograph (HPLC) equipped with a C18 separation column and a UV detector. The mobile phase was a mixture of methanol and water with a volume ratio of $80: 20$ and the wavelength of the ultraviolet radiation was set at $254 \mathrm{~nm}$. The selectivity of active quinones can be calculated by the equation:

$$
S=\frac{n^{t}(\mathrm{EAQ})+n^{t}\left(\mathrm{H}_{4} \mathrm{EAQ}\right)}{n^{0}(\mathrm{EAQ})} \times 100 \%
$$

\section{Results}

\subsection{Structural and morphological properties}

Table 1 shows the basic characteristics of the catalysts. The $\gamma$ $\mathrm{Al}_{2} \mathrm{O}_{3}$ support exhibits a mesoporous structure with $S_{\text {BET }}=$ $167.6 \mathrm{~m}^{2} \mathrm{~g}^{-1}, V_{\mathrm{p}}=0.54 \mathrm{~cm}^{3} \mathrm{~g}^{-1}, D_{\mathrm{p}}=12.8 \mathrm{~nm}$. The surface area and pore size of the support change only slightly after loading with the metallic components, indicating that the $\gamma-\mathrm{Al}_{2} \mathrm{O}_{3}$ is an excellent support for the PdRu catalyst. The decrease of the surface area and pore size compared to $\gamma-\mathrm{Al}_{2} \mathrm{O}_{3}$ is attributed to pore blockage caused by the metallic components during catalyst preparation. ${ }^{42}$

Table 1 also shows the metal contents of the samples measured by ICP. The amounts of Pd and $\mathrm{Ru}$ in the catalysts measured by ICP are lower than the theoretical values, which may be due to the incomplete adsorption of $\mathrm{Pd}$ and $\mathrm{Ru}$ metal ions onto the $\mathrm{Al}_{2} \mathrm{O}_{3}$ support. These phenomena were always observed in the catalysts preparation process by impregnation method. ${ }^{\mathbf{4}, \mathbf{4 2 - 4 4}}$

\subsection{TEM}

The TEM analysis was performed to investigate the morphological features. For each sample, particles in several images are selected randomly to obtain the size distributions. The typical TEM, particle size distribution histograms and HRTEM of mono-Pd, 0.6Pd1.2Ru, mono-Ru are shown in Fig. 1. The sphere-like particles can be seen obviously in each samples, which may be due to the minimization of surface energy, and not many particles can be found in a single image may be attributed to the low loading amount and high dispersion. As shown in Fig. 1, the average particle size of Pd derives from TEM analysis is about $4.13 \mathrm{~nm}$. The average particle size of $1.6 \mathrm{Ru}$ is larger $(6.21 \mathrm{~nm})$ than that of $0.6 \mathrm{Pd}$, which may be due to the fact that $\mathrm{Ru}$ was more mobile on the surface or across the pores of the support during the preparation process in the view of the metal-support interaction. ${ }^{40}$ For the PdRu bimetallic catalysts, the nanoparticles are also spherical type, very similar to the case of monometallic Pd and Ru samples. The average particle size of $0.6 \mathrm{Pd} 1.2 \mathrm{Ru}$ samples $(4.85 \mathrm{~nm})$ is slightly larger than monometallic Pd but smaller than monometallic $\mathrm{Ru}$, which can be ascertained by the statistics. These results may be explained by the consequence of geometric effect between $\mathrm{Pd}$ and $\mathrm{Ru}$. The typical TEM, particle size distribution histograms of $0.6 \mathrm{Pd} 0.4 \mathrm{Ru}, 0.6 \mathrm{Pd} 0.8 \mathrm{Ru}$ and $0.6 \mathrm{Pd} 1.6 \mathrm{Ru}$ are also shown in Fig. S1. $\dagger$ As we can see, the average particle size of $0.6 \mathrm{Pd} 0.4 \mathrm{Ru}$ and $0.6 \mathrm{Pd} 0.8 \mathrm{Ru}$ is $4.24 \mathrm{~nm}$ and $4.35 \mathrm{~nm}$ respectively. The 0.6Pd1.6Ru sample shows a large particle size $(5.76 \mathrm{~nm})$, indicating that an excessive $\mathrm{Ru}$ loading may cause the metallic particles to aggregate.

The HRTEM images are also shown in Fig. 1. The lattice fringe at $0.224 \mathrm{~nm}$ can be detected in mon-Pd, which can be

\begin{tabular}{|c|c|c|c|c|c|}
\hline Sample & $\mathrm{Pd}^{a}(\mathrm{wt} \%)$ & $\mathrm{Ru}^{a}(\mathrm{wt} \%)$ & $S_{\mathrm{BET}}^{b}\left(\mathrm{~m}^{2} \mathrm{~g}^{-1}\right)$ & $V_{\mathrm{p}}{ }^{b}\left(\mathrm{~cm}^{3} \mathrm{~g}^{-1}\right)$ & $D_{\mathrm{p}}^{b}(\mathrm{~nm})$ \\
\hline $\mathrm{Al}_{2} \mathrm{O}_{3}$ & - & - & 167.6 & 0.54 & 12.8 \\
\hline $0.6 \mathrm{Pd}$ & 0.51 & - & 164.9 & 0.51 & 12.2 \\
\hline $0.6 \mathrm{Pd} 0.8 \mathrm{Ru}$ & 0.50 & 0.63 & 161.0 & 0.47 & 12.0 \\
\hline $0.6 \mathrm{Pd} 1.2 \mathrm{Ru}$ & 0.50 & 0.99 & 158.5 & 0.47 & 12.0 \\
\hline $0.6 \mathrm{Pd} 1.6 \mathrm{Ru}$ & 0.49 & 1.25 & 155.3 & 0.46 & 11.9 \\
\hline
\end{tabular}

Table 1 Structural and morphological properties of the catalysts and bare support

${ }^{a}$ As determined by ICP. ${ }^{b}$ BET surface area, total pore volume $\left(V_{\mathrm{p}}\right)$ and average pore diameter $\left(D_{\mathrm{p}}\right)$ were measured from the $\mathrm{N}_{2}$ adsorptiondesorption isotherms. 
attributed to the $\mathrm{Pd}(111)$, and mom-Ru shows a lattice fringe at $0.204 \mathrm{~nm}$ which can be ascribed to the $\mathrm{Ru}$ (101) plane. For $0.6 \mathrm{Pd} 1.2 \mathrm{Ru}$ sample, the plane spacing of $0.217 \mathrm{~nm}$ can be detected, which doesn't accord with any lattice fringes of Pd and $\mathrm{Ru}$, suggesting that the PdRu alloy may be formed in the bimetallic catalysts. ${ }^{44-46}$

Additionally, we have performed TEM-EDS to detect the distribution of Pd and Ru in PdRu bimetallic system. As can be seen in Fig. S2, $\uparrow$ the relevant EDS spectrum recorded from the corresponding region includes signals corresponding to $\mathrm{Pd}$ and $\mathrm{Ru}$.

In order to gain a better understanding of the microstructure of the PdRu particles, the samples were also observed using TEM-HAADF, line-scanning EDS and EDS mapping. As shown in Fig. S3, $\uparrow$ the EDS line scanning analysis demonstrates that the Pd signals and Ru signals almost homogeneous distribution in the PdRu particle, and the relevant EDS mapping results also reveal the homogeneous distribution of $\mathrm{Pd}$ and $\mathrm{Ru}$, which can further confirm the formation of PdRu alloy. ${ }^{\mathbf{4 4}}$

In addition, the Pd particle with a plane spacing of $0.224 \mathrm{~nm}$ and $\mathrm{Ru}$ particle with a plane spacing of $0.204 \mathrm{~nm}$ are detected in the 0.6Pd1.2Ru sample (see Fig. S4 $\dagger$ ), demonstrating that a fraction of Pd or Ru don't form bimetallic particle. The similar phenomenon have also been observed by other researches, which may be due to the disadvantage of the co-impregnation method. ${ }^{\mathbf{4 0 , 4 5}}$
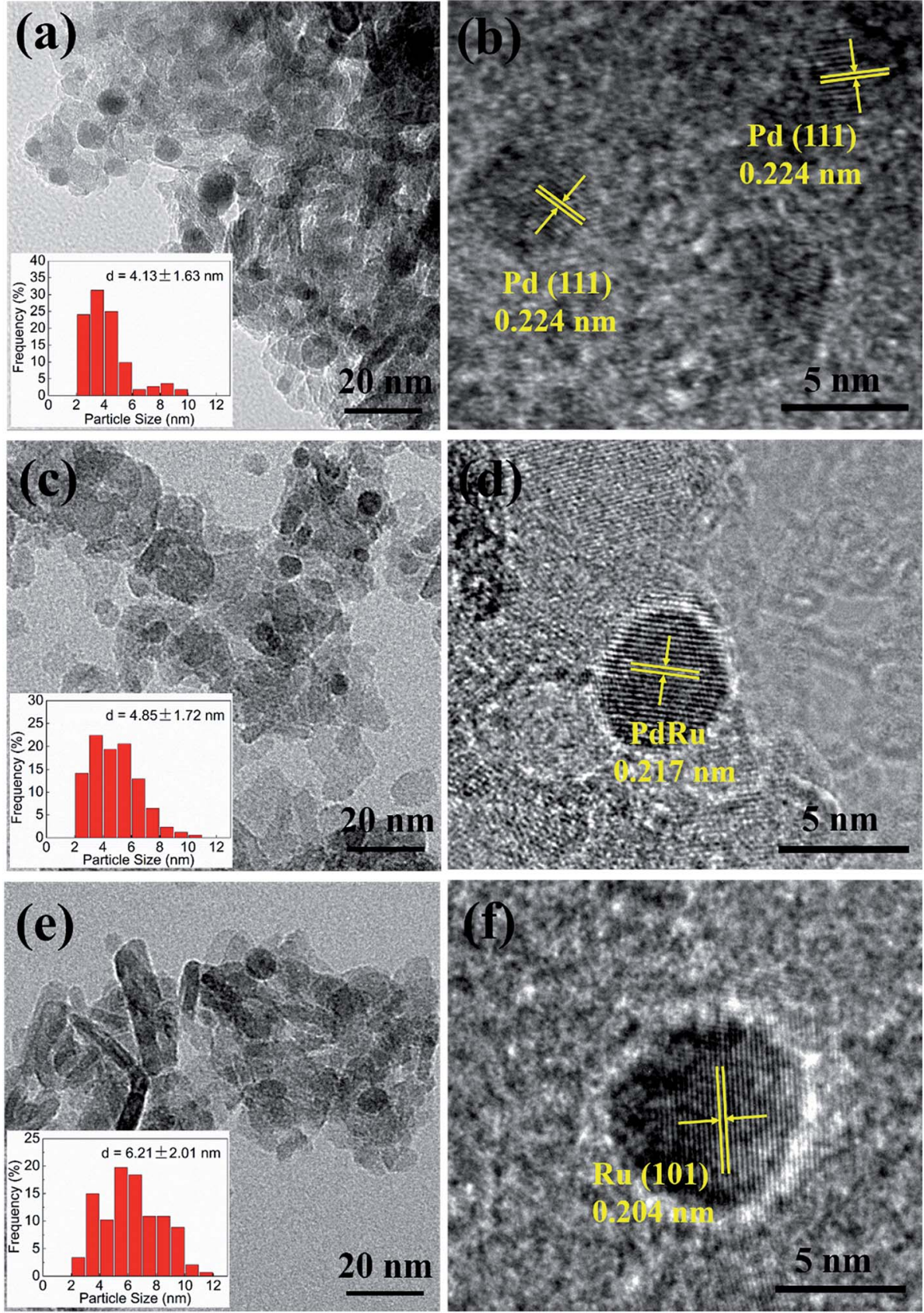

Fig. 1 TEM and HRTEM images of the fresh reduced catalysts, (a) and (b) 0.6Pd, (c) and (d) 0.6Pd1.2Ru, (e) and (f) 1.6Ru. 


\subsection{XRD}

The XRD patterns of the $\gamma-\mathrm{Al}_{2} \mathrm{O}_{3}$ and the catalysts after reduction treatment are shown in Fig. 2. Compared with pure $\gamma-\mathrm{Al}_{2} \mathrm{O}_{3}$, the XRD patterns of the mono-Pd, bimetallic PdRu and mono$\mathrm{Ru}$ samples only change slightly, indicating that the mesoporous structure of $\gamma-\mathrm{Al}_{2} \mathrm{O}_{3}$ is well retained after supporting with metal components. Peaks locate at $2 \theta=38.4^{\circ}, 42.2^{\circ}, 44.0^{\circ}$, $69.4^{\circ}, 78.4^{\circ}, 86.0^{\circ}$ correspond to the (100), (002), (101), (110), (103), (201) planes of Ru metal (JCPDS Card no. 06-0663). As shown in Fig. 2, no any characteristic peaks of Pd are observed, which can be explained by the low loading amount or may be attributed to the overlapping with the broad and high-intensity peaks of $\gamma-\mathrm{Al}_{2} \mathrm{O}_{3}$ support.

\section{$3.4 \mathrm{H}_{2}$-TPR}

The reducibility of the unreduced samples and the possible interactions between $\mathrm{Pd}$ and $\mathrm{Ru}$ were investigated by $\mathrm{H}_{2}$-TPR. The $\mathrm{H}_{2}$-TPR spectra for the various catalysts are presented in Fig. 3. For mono-Pd sample, peaks observed at $107.5^{\circ} \mathrm{C}$ should be ascribed to the reduction of surface $\mathrm{PdO}$, and the $\mathrm{H}_{2}$ consumption peaks show at $371.0{ }^{\circ} \mathrm{C}$ may be attributed to the reduction of subsurface oxidized palladium species. ${ }^{35,47}$ The 1.6Ru catalyst exhibits a $\mathrm{H}_{2}$ consumption peaks at $256.0{ }^{\circ} \mathrm{C}$, which may be due to the reduction of $\mathrm{RuO}_{2}$. For the $\mathrm{PdRu}$ samples, it is obvious that bimetallic cases cause significant change for the reduction behaviors. For all PdRu samples, the reduction peaks of PdO shift to a higher temperature. On the contrary, when compared with mono- $\mathrm{Ru}$, the reduction peak of $\mathrm{Ru}$ in the PdRu samples shift to a lower temperature. In addition, it is worth noting that no obvious negative peak assigned to $\mathrm{PdH}_{x}$ decomposition can be observed for any samples. As $\mathrm{PdH}_{x}$ decreasing with the decrease of metal particle size, this result may be an evidence of the relatively small average particle size and high metal dispersion of the samples. ${ }^{48}$ These results can be attributed to the interaction between the $\mathrm{Pd}$ and $\mathrm{Ru}$ species.

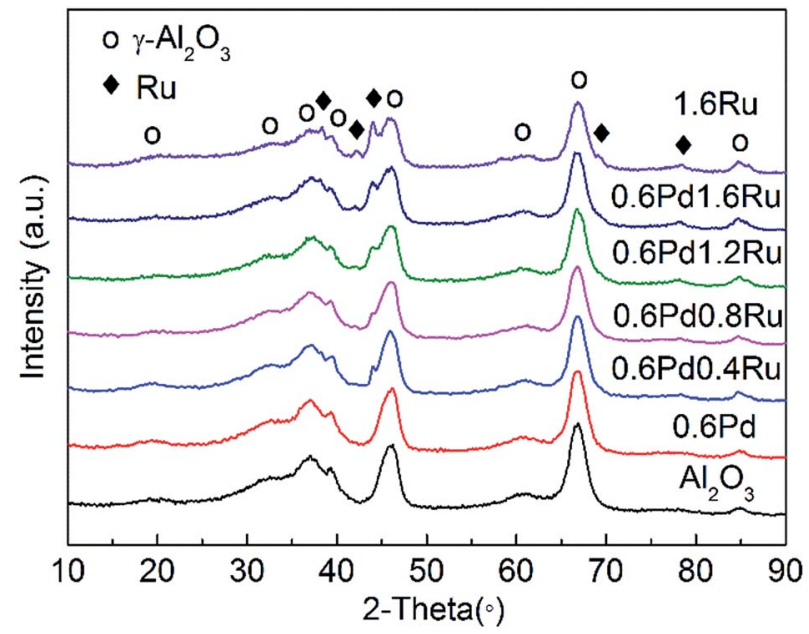

Fig. 2 XRD patterns of the $\gamma-\mathrm{Al}_{2} \mathrm{O}_{3}, 0.6 \mathrm{Pd}, 0.6 \mathrm{Pd0} .4 \mathrm{Ru}, 0.6 \mathrm{Pd0} .8 \mathrm{Ru}$, 0.6Pd1.2Ru, 0.6Pd1.6Ru, and 1.6Ru samples.

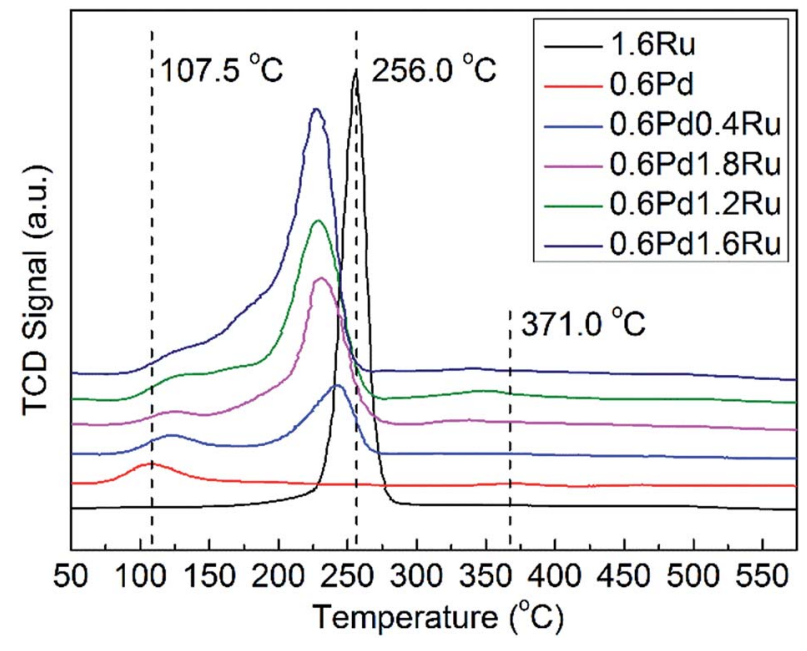

Fig. $3 \mathrm{H}_{2}$-TPR patterns of different samples.

\section{$3.5 \quad \mathrm{H}_{2}$-TPD}

$\mathrm{H}_{2}$-TPD were performed to investigate the correlation between sites and hydrogenation performances of the catalysts from the view of hydrogen supply, and the $\mathrm{H}_{2}$-TPD results for all samples were given in Fig. 4. As can be observed in Fig. 4, the desorption peak at $167{ }^{\circ} \mathrm{C}$ can be attributed to the chemisorbed hydrogen for $0.6 \mathrm{Pd}$, and $\mathrm{H}_{2}$ desorption peak is detected at $199{ }^{\circ} \mathrm{C}$ for 1.6Ru.

The peak intensity of PdRu bimetallic samples is obviously stronger than that of monometallic Pd and Ru. According to the results shown in Table 2, the desorption amount of $\mathrm{H}_{2}$ of PdRu samples is even larger than the sum of $0.6 \mathrm{Pd}$ and $1.6 \mathrm{Ru}$ except for $0.6 \mathrm{Pd} 0.4 \mathrm{Ru}$, which may be due to the low $\mathrm{Ru}$ loading amount. In addition, the desorption amount of $\mathrm{H}_{2}$ of bimetallic samples are enhanced as the amount of Ru increased from $0.4 \%$ to $1.2 \%$ but decrease slightly for $\mathrm{Ru}$ contents of $1.6 \%$, in accordance with the tendency of the catalytic performance. These results indicate that PdRu bimetallic systems show stronger hydrogen desorption behaviors, which may be

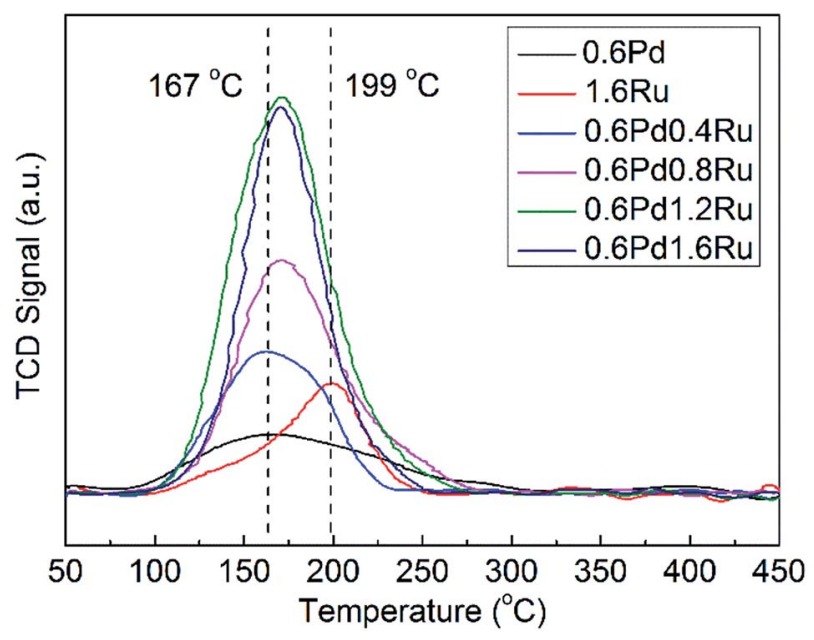

Fig. $4 \mathrm{H}_{2}$-TPD patterns of the different samples. 
Table 2 The desorption amount of $\mathrm{H}_{2}$ over all samples

\begin{tabular}{ll}
\hline Sample & Total amounts $\left(\mu \mathrm{mol} \mathrm{g}_{\text {catalyst }}{ }^{-1}\right)$ \\
\hline $0.6 \mathrm{Pd}$ & 2.46 \\
$0.6 \mathrm{Pd} 0.4 \mathrm{Ru}$ & 4.18 \\
$0.6 \mathrm{Pd} 0.8 \mathrm{Ru}$ & 5.60 \\
$0.6 \mathrm{Pd} 1.2 \mathrm{Ru}$ & 9.05 \\
$0.6 \mathrm{Pd} 1.6 \mathrm{Ru}$ & 7.28 \\
1.6Ru & 2.19
\end{tabular}

attributed to the intense metal-metal and metal-support interactions.

\subsection{XPS}

XPS investigations were carried out to get further insight into the interactions between Ru and Pd and the valence states of the surface metal species for those samples. The Pd 3d and Ru 3p3/ 2 spectra of the catalysts are shown in Fig. 5. The binding energies are referenced to the $\mathrm{C} 1 \mathrm{~s}$ line at $284.8 \mathrm{eV}$.

As shown in Fig. 5, a positive shift $(0.1-0.8 \mathrm{eV})$ of the $\mathrm{Pd} 3 \mathrm{~d}$ binding energy can be observed for the of PdRu bimetallic catalysts with respect to $0.6 \mathrm{Pd}$, indicating that a change in the electronic properties of Pd atom modified upon alloying with $\mathrm{Ru}$, which can be also identified by the binding energy shift of $\mathrm{Ru}$. As the $\mathrm{Ru} 3 \mathrm{~d} 3 / 2$ and $\mathrm{Ru}^{n+} 3 \mathrm{~d} 5 / 2$ peaks overlaps with that of $\mathrm{C}$ 1s, the $\mathrm{Ru} 3 \mathrm{p} 3 / 2$ XPS signal are employed for all catalysts to research the chemical state of $\mathrm{Ru} .^{37,44}$ The peaks at $461.0 \mathrm{eV}$ and $463.4 \mathrm{eV}$ are assigned to the $\mathrm{Ru} 3 \mathrm{p} 3 / 2$ line of $\mathrm{Ru}^{0}$ and $\mathrm{Ru}^{4+}$ supported on $\gamma-\mathrm{Al}_{2} \mathrm{O}_{3} \cdot{ }^{49}$ Compared with $1.6 \mathrm{Ru}$, the $\mathrm{Ru} 3 \mathrm{p} 3 / 2$ binding energy of PdRu bimetallic catalysts presents a negative shift (0.3-0.6 eV) caused by the electronic interaction of Pd and $\mathrm{Ru}$.

For further understanding of the XPS measurement, the valence states of surface Pd and Ru species are derived from the peak-fitting method, and the XPS-derived ratios of oxidized and reduced metal states with different samples are summarized in Tables 3 and 4 . With respect to the mono-Pd sample, the proportion of $\mathrm{Pd}^{2+}$ species increase from $35.9 \%$ to $44.8 \%$ as the amount of $\mathrm{Ru}$ increased. Correspondingly, the proportion of $\mathrm{Ru}^{4+}$ decreased for the bimetallic catalysts compared with the $\mathrm{Ru} / \gamma-\mathrm{Al}_{2} \mathrm{O}_{3}$. Similar changes in the electronic state of $\mathrm{Pd}$ and $\mathrm{Ru}$ in bimetallic PdRu samples had also been found by other researches earlier, implying the obvious interactions between Pd and Ru for the bimetallic catalysts. ${ }^{44,45}$

\subsection{Catalytic performance}

The catalytic performance of all catalysts under the given reaction conditions are shown in Table 5. As we can see, 1.6Ru shows a low activity $\left(0.8 \mathrm{~g} \mathrm{~L}^{-1}\right)$ under our given reaction condition, while $0.6 \mathrm{Pd}$ exhibits a hydrogenation efficiency of $10.1 \mathrm{~g} \mathrm{~L} \mathrm{~L}^{-1}$, corresponding to a $\mathrm{H}_{2} \mathrm{O}_{2}$ productivity of 1581.3 $\mathrm{gH}_{2} \mathrm{O}_{2}$ per gPd per h. Compared to mon-Pd catalyst and mon$\mathrm{Ru}$, it is evident that the PdRu bimetallic catalysts show a significant improvement in the catalytic performance. All of the bimetallic PdRu catalysts exhibit a higher catalytic activity than monometallic Pd catalyst, indicating the promotion effect of $\mathrm{Ru}$ addition to $\mathrm{Pd}$. In particular, the hydrogenation efficiency increases from $10.1 \mathrm{~g} \mathrm{~L}^{-1}$ to $12.1 \mathrm{~g} \mathrm{~L}^{-1}$ for $0.6 \mathrm{Pd} 1.2 \mathrm{Ru}$.

The effect of hydrogenation time for $0.6 \mathrm{Pd}, 0.6 \mathrm{Pd} 1.2 \mathrm{Ru}$ and 1.6Ru are shown in Fig. 6. As the reaction time proceed, the hydrogenation efficiency for all samples increased. Obviously, the activity of bimetallic catalyst is higher than mon-Pd in the whole process. However, the hydrogenation activity on $1.6 \mathrm{Ru}$ is relatively low under the given reaction time. Respect to the selectivity, all catalysts exhibit high initial selectivity at a relatively low 2-EAQ conversion. With the reaction time going on, the decrease of 2-EAQ selectivity for all samples can be observed. It is worth noting that the 2-EAQ selectivity is well preserved for the bimetallic samples. Hence, the hydrogenation results demonstrate that addition of $\mathrm{Ru}$ to $\mathrm{Pd}$ can improve the catalyst's activity and maintain the high selectivity at the same time for 2-ethylanthraquinone hydrogenation.

The stability and reusability of the catalysts is very important for the catalysts. Hence, recycling experiments were performed to investigate this point. The stability and reusability of $0.6 \mathrm{Pd} 1.2 \mathrm{Ru}$ in contrast with $0.6 \mathrm{Pd}$ was investigated, and the recycling experiment results were shown in Fig. 7. It can be seen that the hydrogenation efficiency of $0.6 \mathrm{Pd} 1.2 \mathrm{Ru}$ decreased slightly after three runs. However, for $0.6 \mathrm{Pd}$, there is a relatively obvious decrease in catalytic activity in the recycling experiments. It should be noted that both $0.6 \mathrm{Pd} 1.2 \mathrm{Ru}$ and $0.6 \mathrm{Pd}$ maintain the high selectivity during the recycling tests.

The changes in the average metal particle diameters of the used samples after three runs were also investigated by TEM and shown in Fig. S5. $\dagger$ The 0.6Pd catalyst shows an increase in the particle size after three runs (from $4.13 \mathrm{~nm}$ to $5.00 \mathrm{~nm}$ ). In contrast, $0.6 \mathrm{Pd} 1.2 \mathrm{Ru}$ catalyst almost keeps the same size after three catalytic runs (from $4.85 \mathrm{~nm}$ to $4.90 \mathrm{~nm}$ ). Furthermore, the metal contents of the fresh and used (after three runs) catalysts was determined by ICP-AES and shown in Table S1. $\dagger$ The result shows that negligible leaching occurred during the catalytic experiments.

These results demonstrate that the $\mathrm{PdRu} / \gamma-\mathrm{Al}_{2} \mathrm{O}_{3}$ doesn't show obvious deactivation during three catalytic runs, illustrating its good stability and reusability.

\section{Discussion}

Addition of Ru can significantly improve the performance of Pd catalysts for 2-ethylanthraquinone hydrogenation process. From the experimental results above, the superior catalytic performance of bimetallic PdRu samples may be caused by the synergistic effects between $\mathrm{Pd}$ and $\mathrm{Ru}$, which can (i) enhance the hydrogen desorption behaviors, (ii) modulate the electronic state of metals and thus promote the activation of 2-ethylanthraquinone molecules.

It is well known that the hydrogen supply plays an important role in the hydrogenation reaction. Due to the intense metalmetal and metal-support interactions, the desorption peak intensity of hydrogen of PdRu bimetallic samples is obviously stronger than that of monometallic Pd and Ru. That's to say, more hydrogen can be supplied to reacted with 2-ethylanthraquinone, leading to a superior hydrogenation 

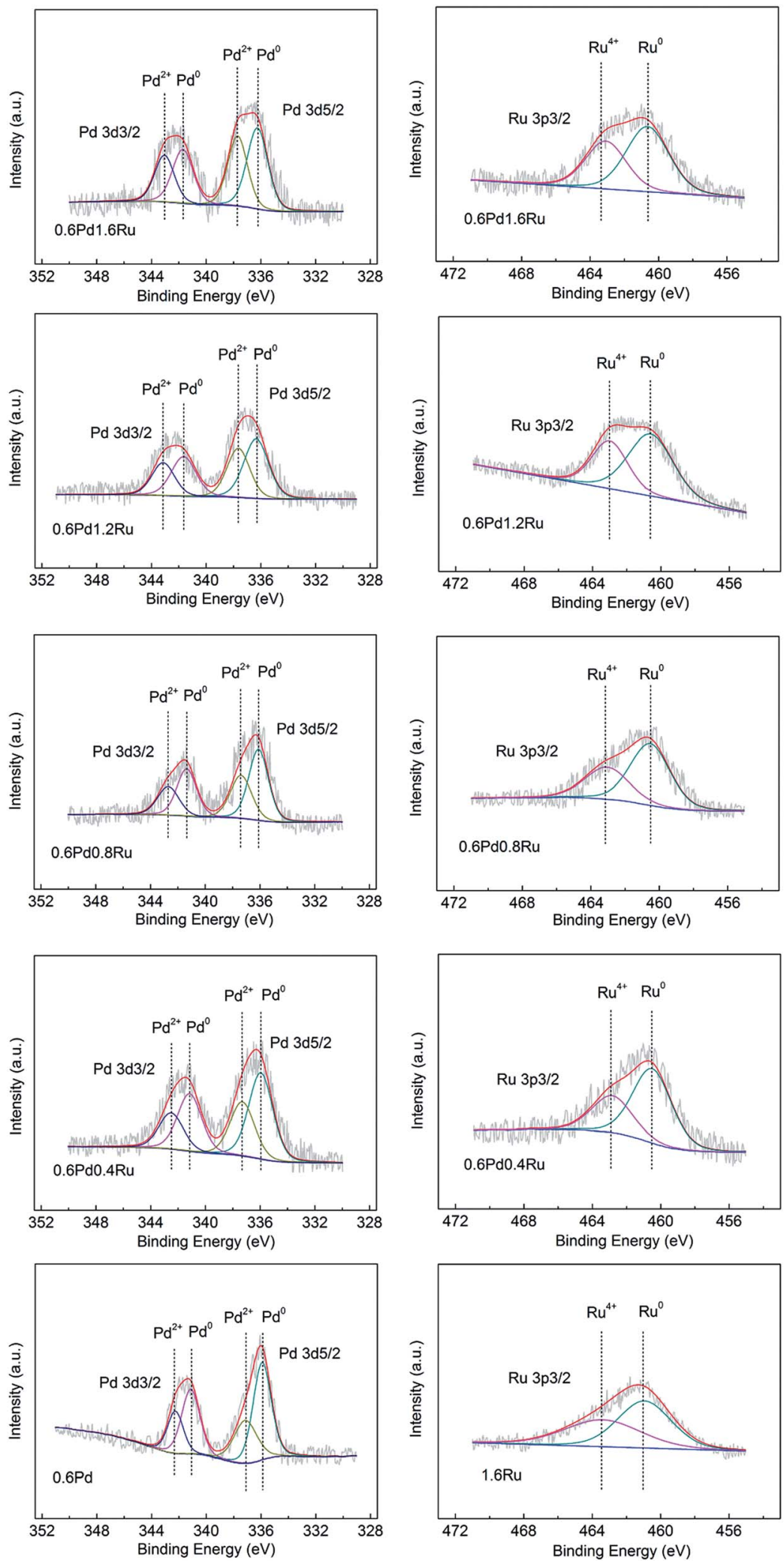

Fig. 5 XPS spectra of Pd 3d and Ru 3p3/2 for the different samples.

performance. In addition, it should be noticed that the activity of $0.6 \mathrm{Pd} 1.6 \mathrm{Ru}$ is lower than that of $0.6 \mathrm{Pd} 1.2 \mathrm{Ru}$. This may be due to the severe aggregation of the metal particles because of the excessive Ru loading, and too many Pd atoms are covered by the $\mathrm{Ru}$ which were unable to supply sufficient active sites, the similar results had also been reported earlier. ${ }^{50,51}$ 
Table 3 Binding energies (eV) and curve-fitting results of Pd $3 d$ XPS spectra

\begin{tabular}{|c|c|c|c|c|c|c|}
\hline \multirow[b]{2}{*}{ Samples } & \multicolumn{2}{|c|}{$\mathrm{Pd} 3 \mathrm{~d} 5 / 2, \mathrm{eV}$} & \multicolumn{2}{|c|}{$\mathrm{Pd} 3 \mathrm{~d} 3 / 2, \mathrm{eV}$} & \multirow[b]{2}{*}{$\mathrm{Pd}^{0} \%$} & \multirow[b]{2}{*}{$\mathrm{Pd}^{2+} \%$} \\
\hline & $\mathrm{Pd}^{0}$ & $\mathrm{Pd}^{2+}$ & $\mathrm{Pd}^{0}$ & $\mathrm{Pd}^{2+}$ & & \\
\hline $0.6 \mathrm{Pd}$ & 335.9 & 337.1 & 341.1 & 342.3 & 64.1 & 35.9 \\
\hline $0.6 \mathrm{Pd} 0.4 \mathrm{Ru}$ & 336.0 & 337.2 & 341.2 & 342.4 & 61.2 & 38.8 \\
\hline $0.6 \mathrm{Pd} 0.8 \mathrm{Ru}$ & 336.1 & 337.4 & 341.4 & 342.6 & 60.4 & 39.6 \\
\hline $0.6 \mathrm{Pd} 1.2 \mathrm{Ru}$ & 336.3 & 337.6 & 341.6 & 343.1 & 56.8 & 43.2 \\
\hline $0.6 \mathrm{Pd} 1.6 \mathrm{Ru}$ & 336.3 & 337.7 & 341.7 & 343.1 & 55.2 & 44.8 \\
\hline
\end{tabular}

Table 4 Binding energies (eV) and curve-fitting results of Ru 3p3/2 XPS spectra

\begin{tabular}{|c|c|c|c|c|}
\hline \multirow[b]{2}{*}{ Samples } & \multicolumn{2}{|c|}{$\mathrm{Ru} 3 \mathrm{p} 3 / 2, \mathrm{eV}$} & \multirow[b]{2}{*}{$\mathrm{Ru}^{0} \%$} & \multirow[b]{2}{*}{$\mathrm{Ru}^{4+} \%$} \\
\hline & $\mathrm{Ru}^{4+}$ & $\mathrm{Ru}^{0}$ & & \\
\hline $0.6 \mathrm{Pd} 0.4 \mathrm{Ru}$ & 462.8 & 460.5 & 65.8 & 34.2 \\
\hline $0.6 \mathrm{Pd} 0.8 \mathrm{Ru}$ & 463.0 & 460.5 & 63.5 & 36.5 \\
\hline $0.6 \mathrm{Pd} 1.2 \mathrm{Ru}$ & 463.0 & 460.6 & 61.9 & 38.1 \\
\hline $0.6 \mathrm{Pd} 1.6 \mathrm{Ru}$ & 463.1 & 460.7 & 58.8 & 41.2 \\
\hline $1.6 \mathrm{Ru}$ & 463.4 & 461.0 & 54.9 & 45.1 \\
\hline
\end{tabular}

Table 5 The performance of all the catalysts for 2-ethylanthraquinone hydrogenation $^{a}$

\begin{tabular}{llll}
\hline Catalysts & $\begin{array}{l}B \\
\left(\mathrm{~g} \mathrm{~L}^{-1}\right)\end{array}$ & Selectivity & $\begin{array}{l}\text { Productivity }\left(\mathrm{gH}_{2} \mathrm{O}_{2} \text { per }\right. \\
\text { gPd per } \mathrm{h})\end{array}$ \\
\hline 0.6Pd & 10.1 & $99.5 \%$ & 1581.3 \\
0.6Pd0.4Ru & 11.1 & $99.5 \%$ & 1707.7 \\
0.6Pd0.8Ru & 11.6 & $99.6 \%$ & 1851.3 \\
0.6Pd1.2Ru & 12.1 & $99.5 \%$ & 1942.2 \\
0.6Pd1.6Ru & 11.8 & $99.4 \%$ & 1923.5 \\
$0.4 \mathrm{Ru}$ & 0 & $99.9 \%$ & - \\
$0.8 \mathrm{Ru}$ & 0.3 & $99.6 \%$ & - \\
1.2Ru & 0.4 & $99.5 \%$ & - \\
1.6Ru & 0.8 & $99.4 \%$ & -
\end{tabular}

${ }^{a}$ Reaction conditions: catalysts: $0.3 \mathrm{~g}, \mathrm{H}_{2}$ pressure: $0.3 \mathrm{MPa}$, temperature: $60^{\circ} \mathrm{C}$, reaction time: $15 \mathrm{~min}$.

With respect to the electronic factor, electropositive species can act as electrophilic sites for the adsorption and activation of $\mathrm{C}=\mathrm{O}$ through the lone electron pair of the oxygen atoms, known as the "electrophilic $\mathrm{C}=\mathrm{O}$ activation" mechanism, can favored the hydrogenation of $\mathrm{C}=\mathrm{O} .{ }^{52}$ For example, Richard et al. found that the appropriate $\mathrm{Fe}^{\delta+}$ deposited on Pt particles can act as an adsorption site for the $\mathrm{C}=\mathrm{O}$ group of the cinnamaldehyde and then improve the activity and selectivity of platinum for the liquid-phase hydrogenation of cinnamaldehyde into cinnamyl alcohol. ${ }^{50}$ Hirschl et al. reported that an electropositive iron could transfer charge to the oxygen atom thus activating the hydrogenation of carbonyl group. ${ }^{53}$ Koo-amornpattana et al. suggested that electropositive metal $\left(\mathrm{Li}^{+}, \mathrm{Na}^{+}\right.$and $\left.\mathrm{K}^{+}\right)$can enhance the activation of $\mathrm{C}=\mathrm{O} .{ }^{54}$

Many researches have also observed that electropositive Pd or $\mathrm{Ru}$ could act as electrophilic sites for the adsorption and activation of the $\mathrm{C}=\mathrm{O}$ through the lone electron pair of oxygen atoms and favored the hydrogenation of $\mathrm{C}=\mathrm{O}$. For example, Mironenko et al. reported that the enhanced catalytic performance of $\mathrm{Pd}-\mathrm{Ru} / \mathrm{C}$ catalysts in hydrogenation of benzaldehyde may be due to facilitation of electrophilic activation of the $\mathrm{C}=\mathrm{O}$ owing to an increased fraction of the electron-deficient $\mathrm{Pd}$ species. ${ }^{45}$ Mistri et al. observed that addition $\mathrm{Ru}$ to $\mathrm{Pd} / \mathrm{CeO}_{2}$ can enhance its activity and selectivity for hydrogenation of $p$ chloronitrobenzene due to the remarkable $\mathrm{Ru}^{4+}$ promotion effect. ${ }^{55}$ Teddy et al. found that the electropositive Ru atoms in the PtRu/CNT catalyst acts as electrophilic site for the adsorption and activation of the $\mathrm{C}=\mathrm{O}$ bond via the lone electron pair of the oxygen atoms, and permits to increase the selectivity of cinnamaldehyde hydrogenation towards cinnamyl alcohol. ${ }^{56}$

Here our study suggests that the promoting role of Ru may be explained via the "electrophilic $\mathrm{C}=\mathrm{O}$ activation". As evidenced by XPS analysis, the electronic interaction between Pd and $\mathrm{Ru}$ causes an increased fraction of electron-deficient Pd species in the bimetallic samples. On the other hand, $\mathrm{Ru}^{4+}$ exists in each samples, and the amount of $\mathrm{Ru}^{4+}$ increases as the increasing of the loading amount of $\mathrm{Ru}$. The interpretation of the promoting effects may be suggested as follow. The dissociative adsorption of the hydrogen molecule in the surface of metallic Pd and Ru can make easy supply of hydride ion. $\mathrm{Pd}^{2+}$ and $\mathrm{Ru}^{4+}$ can act as the electrophilic sites for the adsorption and activation of the $\mathrm{C}=\mathrm{O}$ through the lone electron pair of the oxygen atoms, which may be conducive to the hydrogenation of $\mathrm{C}=\mathrm{O}$ and enhance the performance of PdRu catalysts (see Fig. 8). This interpretation is also confirmed by the catalytic performance described above.
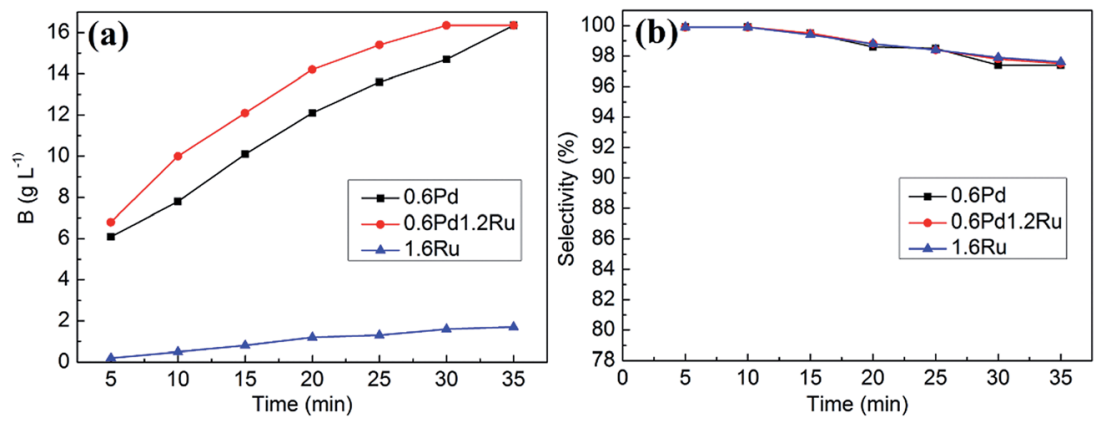

Fig. 6 Hydrogenation efficiency and selectivity of 2-EAQ hydrogenation on 0.6Pd, 0.6Pd1.2Ru and 1.6Ru in different reaction time under 0.3MPa $P_{\mathrm{H}_{2}}$ at $60^{\circ} \mathrm{C}$. (a) Hydrogenation efficiency, (b) 2-EAQ selectivity. 

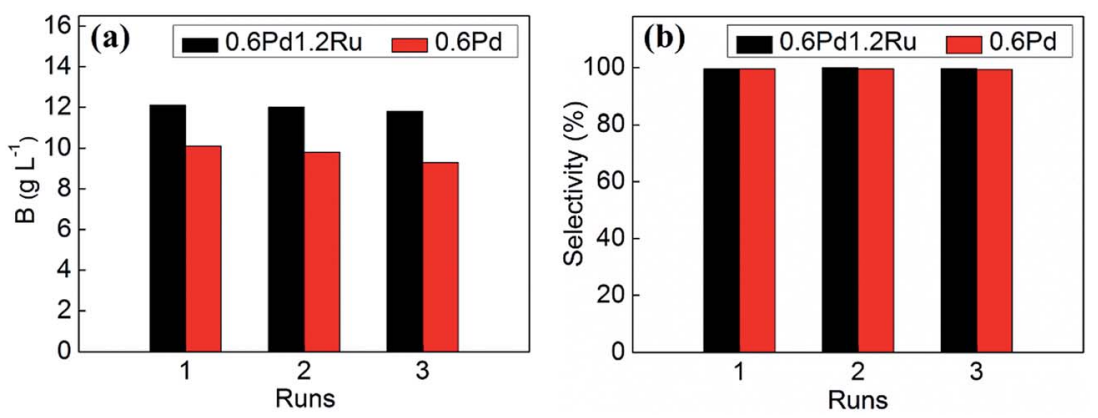

Fig. 7 Comparison of reusability of the $0.6 \mathrm{Pd} 1.2 \mathrm{Ru}$ and $0.6 \mathrm{Pd}$ : (a) hydrogenation efficiency, (b) 2-EAQ selectivity. Reaction condition: catalysts: $0.3 \mathrm{~g}, \mathrm{H}_{2}$ pressure: $0.3 \mathrm{MPa}$, temperature: $60^{\circ} \mathrm{C}$, reaction time: $15 \mathrm{~min}$.

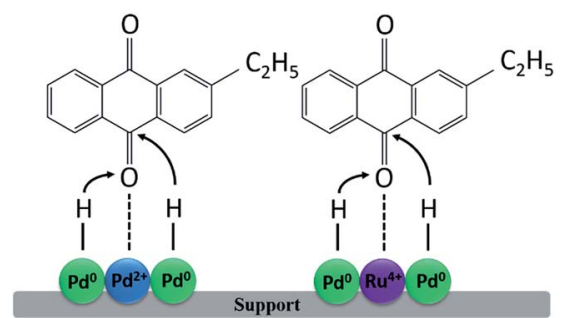

Fig. 8 The proposed mechanism of promoting effect of a second metal in bimetallic $\mathrm{PdRu} / \gamma-\mathrm{Al}_{2} \mathrm{O}_{3}$ samples and the preferential modes of 2-ethylanthraquinone activation on their surface.

\section{Conclusion}

In this work, PdRu bimetallic catalysts supported on gamma alumina were prepared by a facile incipient wetness impregnation method for the 2-ethylanthraquinone hydrogenation. It is found that the addition of Ru to Pd can improve the catalyst's activity and maintain the high selectivity at the same time. The excellent catalytic performance of the bimetallic catalysts in this reaction system can be attributed to the synergistic effects between Pd and $\mathrm{Ru}$.

(i) Due to the intense metal-metal and metal-support interactions, more hydrogen can be adsorbed and dissociated on PdRu bimetallic system in contrast to the monometallic cases, as evidenced by $\mathrm{H}_{2}$-TPD results, which may favor the hydrogenation effect of the PdRu catalysts.

(ii) The XPS results also indicate the intensified electronic interactions between the two metals. The higher fraction of $\mathrm{Pd}^{2+}$ and the presence of $\mathrm{Ru}^{4+}$ in the PdRu system may act as the electrophilic sites for the adsorption and activation of the $\mathrm{C}=\mathrm{O}$ of the 2-ethylanthraquinone molecule through the lone electron pair of the oxygen atoms, which may be conducive to the hydrogenation of $\mathrm{C}=\mathrm{O}$ and enhance the performance of PdRu catalysts.

\section{Acknowledgements}

This work was supported by the National Natural Science Foundation of China $(21276179,21576205)$ and the Program for Changjiang Scholars, Innovative Research Team in University (IRT_15R46).

\section{References}

1 J. M. Campos-Martin, G. Blanco-Brieva and J. L. G. Fierro, Angew. Chem., Int. Ed., 2006, 45, 6962-6984.

2 H. Yao, C. Shen, Y. Wang and G. Luo, RSC Adv., 2016, 6, 23942-23948.

3 G. Blanco-Brieva, M. Montiel-Argaiz, F. Desmedt, P. Miquel, J. M. Campos-Martin and J. L. G. Fierro, $R S C$ Adv., 2016, 6, 99291-99296.

4 Y. Han, Z. He, S. Wang, W. Li and J. Zhang, Catal. Sci. Technol., 2015, 5, 2630-2639.

5 J. Tan, J. Zhang, Y. Lu, J. Xu and G. Luo, AIChE J., 2012, 58, 1326-1335.

6 S. Melada, R. Rioda, F. Menegazzo, F. Pinna and G. Strukul, J. Catal., 2006, 239, 422-430.

7 J. García-Serna, T. Moreno, P. Biasi, M. J. Cocero, J. P. Mikkola and T. P. Salmi, Green Chem., 2014, 16, 2320.

8 Y. Isaka, Y. Yamada, T. Suenobu, T. Nakagawa and S. Fukuzumi, RSC Adv., 2016, 6, 42041-42044.

9 S. J. Freakley, Q. He, J. H. Harrhy, L. Lu, D. A. Crole, D. J. Morgan, E. N. Ntainjua, J. K. Edwards, A. F. Carley, A. Y. Borisevich, C. J. Kiely and G. J. Hutchings, Science, 2016, 351, 965-968.

10 R. Hong, J. Feng, Y. He and D. Li, Chem. Eng. Sci., 2015, 135, 274-284.

11 Y. Li, J. Feng, Y. He, D. G. Evans and D. Li, Ind. Eng. Chem. Res., 2012, 51, 11083-11090.

12 H. Shang, H. Zhou, Z. Zhu and W. Zhang, J. Ind. Eng. Chem., 2012, 18, 1851-1857.

13 T. Kamachi, T. Ogata, E. Mori, K. Iura, N. Okuda, M. Nagata and K. Yoshizawa, J. Phys. Chem. C, 2015, 119, 8748-8754.

14 P. Tang, Y. Chai, J. Feng, Y. Feng, Y. Li and D. Li, Appl. Catal., A, 2014, 469, 312-319.

15 X. Li, H. Su, G. Ren and S. Wang, RSC Adv., 2015, 5, 100968100977.

16 H. Chen, D. Huang, X. Su, J. Huang, X. Jing, M. Du, D. Sun, L. Jia and Q. Li, Chem. Eng. J., 2015, 262, 356-363.

17 A. Drelinkiewicz and A. Waksmundzka-Góra, J. Mol. Catal. A: Chem., 2006, 246, 167-175.

18 D. M. Alonso, S. G. Wettstein and J. A. Dumesic, Chem. Soc. Rev., 2012, 41, 8075-8098. 
19 X. Yang, D. Chen, S. Liao, H. Song, Y. Li, Z. Fu and Y. Su, J. Catal., 2012, 291, 36-43.

20 F. Menegazzo, M. Signoretto, M. Manzoli, F. Boccuzzi, G. Cruciani, F. Pinna and G. Strukul, J. Catal., 2009, 268, 122-130.

21 L. Ouyang, G. Da, P. Tian, T. Chen, G. Liang, J. Xu and Y. Han, J. Catal., 2014, 311, 129-136.

22 P. Kittisakmontree, B. Pongthawornsakun, H. Yoshida, S. Fujita, M. Arai and J. Panpranot, J. Catal., 2013, 297, 155-164.

23 Q. Zhang, J. Li, X. Liu and Q. Zhu, Appl. Catal., A, 2000, 197, 221-228.

24 E. Kim, H. S. Jeong and B. M. Kim, Catal. Commun., 2014, 45, 25-29.

25 J. Xu, L. Ouyang, G. Da, Q. Song, X. Yang and Y. Han, J. Catal., 2012, 285, 74-82.

26 S. Chinayon, O. Mekasuwandumrong, P. Praserthdam and J. Panpranot, Catal. Commun., 2008, 9, 2297-2302.

27 X. Jiang, N. Koizumi, X. Guo and C. Song, Appl. Catal., B, 2015, 170-171, 173-185.

28 W. G. Menezes, L. Altmann, V. Zielasek, K. Thiel and M. Bäumer, J. Catal., 2013, 300, 125-135.

29 J. Zhao, X. Xu, X. Li and J. Wang, Catal. Commun., 2014, 43, 102-106.

30 A. Vicente, G. Lafaye, C. Especel, P. Marécot and C. T. Williams, J. Catal., 2011, 283, 133-142.

31 R. Hou, W. Yu, M. D. Porosoff, J. Chen and T. Wang, J. Catal., 2014, 316, 1-10.

32 G. Budroni, S. A. Kondrat, S. H. Taylor, D. J. Morgan, A. F. Carley, P. B. Williams and G. J. Hutchings, Catal. Sci. Technol., 2013, 3, 2746.

33 R. Kosydar, A. Drelinkiewicz, E. Lalik and J. Gurgul, Appl. Catal., A, 2011, 402, 121-131.

34 T. Ding, Y. Qin and Z. Ma, Chin. J. Catal., 2002, 23, 227-230.

35 Y. Han, Z. He, Y. Guan, W. Li and J. Zhang, Acta Phys.-Chim. Sin., 2015, 31, 729-737.

36 E. N. Ntainjua, S. J. Freakley and G. J. Hutchings, Top. Catal., 2012, 55, 718-722.

37 W. Luo, M. Sankar, A. M. Beale, Q. He, C. J. Kiely, P. C. Bruijnincx and B. M. Weckhuysen, Nat. Commun., 2015, 6, 6540 .
38 C. Huang, X. Yang, H. Yang, P. Huang, H. Song and S. Liao, Appl. Surf. Sci., 2014, 315, 138-143.

39 J. Qiu, H. Zhang, X. Wang, H. Han, C. Liang and C. Li, React. Kinet. Catal. Lett., 2006, 88, 269-275.

40 J. Chen, X. Liu and F. Zhang, Chem. Eng. J., 2015, 259, 43-52.

41 K. M. K. Yu, P. Meric and S. C. Tsang, Catal. Today, 2006, 114, 428-433.

42 J. Gu, S. Wang, Z. He, Y. Han and J. Zhang, Catal. Sci. Technol., 2016, 6, 809-817.

43 S. Wang, K. Gao, W. Li and J. Zhang, Appl. Catal., A, 2017, 531, 89-95.

44 M. Tang, S. Mao, M. Li, Z. Wei, F. Xu, H. Li and Y. Wang, ACS Catal., 2015, 5, 3100-3107.

45 R. M. Mironenko, O. B. Belskaya, T. I. Gulyaeva, M. V. Trenikhin, A. I. Nizovskii, A. V. Kalinkin, V. I. Bukhtiyarov, A. V. Lavrenov and V. A. Likholobov, Catal. Today, 2017, 279, 2-9.

46 A. Mitra, D. Jana and G. De, Ind. Eng. Chem. Res., 2013, 52, 15817-15823.

47 N. S. Babu, N. Lingaiah, J. V. Kumar and P. S. S. Prasad, Appl. Catal., A, 2009, 367, 70-76.

48 Y. Liu, Y. He, D. Zhou, J. Feng and D. Li, Catal. Sci. Technol., 2016, 6, 3027-3037.

49 J. Okal and M. Zawadzki, Appl. Catal., B, 2009, 89, 22-32.

50 D. Richard, J. Ockelford, A. G. Fendler and P. Gallezot, Catal. Lett., 1989, 3, 53-58.

51 Y. Zhao, S. Zhao, Y. Geng, Y. Shen, H. Yue, J. Lv, S. Wang and X. Ma, Catal. Today, 2016, 276, 28-35.

52 P. Mäki-Arvela, J. Hájek, T. Salmi and D. Y. Murzin, Appl. Catal., A, 2005, 292, 1-49.

53 R. Hirschl, F. Delbecq, P. Sautet and J. Hafner, J. Catal., 2003, 217, 354-366.

54 W. Koo-amornpattana and J. M. Winterbottom, Catal. Today, 2001, 66, 277-287.

55 R. Mistri, J. Llorca, B. C. Ray and A. Gayen, J. Mol. Catal. A: Chem., 2013, 376, 111-119.

56 J. Teddy, A. Falqui, A. Corrias, D. Carta, P. Lecante, I. Gerber and P. Serp, J. Catal., 2011, 278, 59-70. 